Supporting Information for:

\title{
Airborne Assessment of Methane Emissions from Offshore Platforms in the U.S. Gulf of Mexico
}

\author{
Alan M. Gorchov Negron, Eric A. Kort, Stephen A. Conley, Mackenzie L. Smith \\ Correspondence to: Alan M. Gorchov Negron (agorchov@umich.edu) and Eric A. Kort \\ (eakort@umich.edu)
}

23 Pages

9 Figures

1 Table

\section{Summary of Supporting Information: \\ Appendix}

S1. Supply Chain of Oil and Gas in the U.S. Gulf of Mexico Basin

S2. Instrumentation

S3. Additional Data

S4. Facility-level Approach

S5. Regional-level Approach

S6. Plume Attribution

S7. Description of Official Inventories and Development of GHGI with Updated Platforms

S8. Discussion of Large Shallow Water Complexes

S9. Development of Producing and Non-producing Platform Segments in the Aerial

Measurement-based Inventory

S10. Sampling Diversity and Expansion of the Aerial Measurement-based Inventory.

S11. Development of Emission Factors Analogous to the GHGI

\section{Figures}

S1. Profiles with Developed Mixed Layers for Jan. 17 -Box A

S2. Profiles with Developed Mixed Layers for Jan. 19 -Box B

S3. Profiles with Developed Mixed Layers for Jan. 23 -Box C

S4. Profiles with Developed Mixed Layers for Jan. 24 -Box C

S5. Loss Rate and Natural Gas Production per Platform

S6. Facility-level Comparison between Aircraft and GOADS Inventory

S7. Downwind Regional Flux Transect for Jan. 19 -Box B

S8. Map of Aerial Measurement-based Inventory for the U.S. Gulf of Mexico

S9. Comparison of Emission Rate Distribution with Yacovitch et al. (2020)

Table

S1. Facility-level Emissions

\section{SI References}




\section{Supplementary Introduction}

\section{S1. Supply Chain of Oil and Gas in the U.S. Gulf of Mexico Basin.}

The supply chain of oil and gas in shallow and deep water show different patterns. In shallow water relatively simple platforms (well protectors and caissons) sit atop wells and transport hydrocarbons to a central hub platform or series of platforms in a complex for processing before the oil and gas can be sent to shore by either export pipeline or barge ${ }^{1,2}$. Some shallow water facilities, especially in federal waters, contain both production and processing equipment and are likely classified as fixed platforms. In deep water a variety of large platforms are used to produce and process oil and gas, which can be exported by new pipeline, barge, or to existing export pipeline connected to central hub shallow water facilities no longer needed for shallow water production ${ }^{1,2}$. These shallow water facilities are a part of a class of platform termed 24-hour manned auxiliary structures, which are a stable class of shallow water facility increasingly used to maintain compression and pipeline transport for deep water production ${ }^{2,3}$.

\section{Supplementary Materials and Methods}

\section{S2. Instrumentation.}

Measurements of methane $\left(\mathrm{CH}_{4}\right)$, carbon dioxide $\left(\mathrm{CO}_{2}\right)$, carbon monoxide $(\mathrm{CO})$, and water vapor $\left(\mathrm{H}_{2} \mathrm{O}\right)$, are collected with the Picarro model 2301-f instrument with wavelength-scanned cavity ringdown spectrometry ${ }^{4}$. Ozone $\left(\mathrm{O}_{3}\right)$ is collected by the 2B 205 Dual Beam Ozone Monitor using two detection cells to simultaneously measure ozone scrubbed and non-scrubbed air. Samples are made at a frequency of $0.5 \mathrm{~Hz}$ with an average precision and accuracy of $1 \mathrm{ppb}$ ${ }^{6}$. GPS antennae, mounted on the Mooney aircraft, recorded latitude, longitude, altitude, aircraft heading, zonal speed, and meridional speed. Horizontal winds are calculated following Conley et al (2014) ${ }^{7}$. Temperature $\left(\mathrm{C}^{\circ}\right)$ and humidity $(\%)$ were collected with the Vaisala HMP60 probe. Aircraft speeds averaged around 70 meters per second.

\section{S3. Additional Data.}

Detailed information on offshore oil and gas industry structures in the Outer Continental Shelf (OCS) is collected from the Bureau of Ocean Energy Management (BOEM) data center at https://www.data.boem.gov/ also available at the Bureau of Safety and Environmental Enforcement. Specifically the structure information for offshore oil and gas structures are collected from Platform/Rig Information ${ }^{8,9}$ and offshore pipelines are collected at Pipeline Information ${ }^{10}$. Venting records reported at the lease-level in federal waters are gathered at Oil and Gas Operations Reports - Part B ${ }^{11}$. Offshore equipment located in state waters are found for 2006 Louisiana structures at Data.gov and for 2018 Texas structures at the Texas General Land Office, but ultimately not incorporated into this study. OCS Equipment and emission information are collected from spatial data reported in the BOEM Gulfwide Offshore Activity Data System (GOADS) found at https://www.boem.gov/Gulfwide-Offshore-Activity-Data-System-GOADS/. Production in the outer continental shelf, Louisiana state waters, and Texas state waters are gathered from Drillinginfo ${ }^{12}$.

\section{S4. Facility-level Approach.}

We use an aircraft sampling method developed by Conley et al. (2017) to quantify emissions from individual sources in an oil and gas basin ${ }^{13}$. During flight, the aircraft makes regular 
upwind and downwind measurements in vertically stratified horizontal loops around a facility, creating a cylindrical flight path (Figure $2 \mathrm{a}$ ). The horizontal flux for each loop is calculated using Gauss's Theorem. The sum of the horizontal fluxes for each loop bin and a temporal mass trend represent emissions in the below equation from Conley et al. (2017) ${ }^{13}$.

$$
Q_{c}=\left\langle\frac{\partial m}{\partial t}\right\rangle+\int_{0}^{z_{\max }} \oint c^{\prime} u_{h} \cdot n d l d z
$$

Where $Q_{c}$ denotes the sum of sources and sinks, $\left\langle\frac{\partial m}{\partial t}\right\rangle$ is the trend in mass averaged over the volume, $z=0$ is the virtual height of lowest loop, $z_{\max }$ is the virtual height of the highest loop affected by the source, $c^{\prime}$ is the perturbation concentration, $u_{h}$ represents horizontal wind speed, and $n$ is a unit vector directed outward.

Loops were flown at a radius of 375-1750 meters and frequency of 8-14 loops per site. Bottom loop heights were made between 3 and 40 meters above sea level. The top loops were made at altitudes between 200-440 meters above sea level where plumes were no longer identifiable. Uncertainty estimates are assigned following Conley et al. (2017) ${ }^{13}$.

Facilities were usually sampled on the same days regional flights were made in the respective area, but some were measured more than once (Table S1). On both January $17^{\text {th }}$ and January $18^{\text {th }}$ sites AS1-AS4 were sampled. On January $19^{\text {th }}$ sites BS6 and BS7 were sampled. On January $22^{\text {nd }}$ AS4 was sampled again. On January $23^{\text {rd }}$ CS8 and CS9 were sampled. And on January $24^{\text {th }}$ CS10-CS13 were sampled.

On two occasions at two sites $\mathrm{CH}_{4}$ concentrations exceeded the Picarro instrument linearity threshold of 7,000 ppb of $\mathrm{CH}_{4}$ (Table S1). We proceed to estimate fluxes noting the additional uncertainty. The similar emission rates found for AS4 in the regional-level estimates lend credence to our facility-level estimate (Table S1).

\section{S5. Regional-level Approach.}

We use the widely implemented mass balance technique. The mass balance method calculates the $\mathrm{CH}_{4}$ flux through an aircraft transect, assuming that the flight passes through the mixed layer of the atmosphere and is sufficiently downwind of $\mathrm{CH}_{4}$ sources that they are mixed vertically throughout the mixed layer column. The technique follows the general form below for an aircraft transect:

$$
f l u x=v \cos (\alpha) \int_{z_{0}}^{z_{1}} \int_{-y}^{y}\left(X(y)-X_{b g}\right) * n(z) d y d z
$$

Where $v$ represents the average wind velocity, $\cos (\alpha)$ is the normal angle of the wind direction to the aircraft transect, $z_{0}$ is the height of the ground, $z_{1}$ is the adjusted mixing height that takes into account entrainment from the mixed layer to the free troposphere as developed by Peischl et al. (2016) ${ }^{14}, y$ is the length of the plume or transect, $\left(X-X_{b g}\right)$ represents the elevated concentrations above local background levels, and $n(z)$ is the density of air. We can simplify this equation for this study using a ground height at sea level and average concentrations over the length of the flight path compared to a background to calculate an enhancement.

Mass balance estimates are made for transects associated with a profile indicating a developed mixed layer. The marine mixed layer was not present on all flight days and not present on all 
profiles. No clear mixed layer developed on Jan. 18 - Box A and Jan. 22 - Box B. On Jan. 17 Box A, Jan. 19. -Box B, Jan. 23 -Box C, and Jan. 24 -Box C a mixed layer was observed on all or some profiles between 100-750 meters. Figures S1-S4 show profiles, flown as low as 3 meters above sea level, where a well-developed mixed layer appears evident. For future sampling, we recommend monitoring surface ocean and air temperature from buoys, and note that best mixing occurs when surface ocean temperature exceeds that of the atmosphere.

We classify our mass balance calculations into two groups: downwind plumes and regional enhancements. Fluxes from large downwind plumes associated with sites AS4 and AS5 in Box A (Figure 2b) are estimated using the downwind concentration values on plume ends as a background. Regional enhancements represent emissions from the entire box and are calculated using the full aircraft transect (Figure 2b).

To estimate measurement uncertainty we propagate errors in wind direction, wind angle, wind speed, background concentrations of $\mathrm{CH}_{4}$, and the height of the mixed layer. Uncertainties in wind parameters are estimated using along track standard deviations. The uncertainty in background $\mathrm{CH}_{4}$ concentrations is made from the standard deviation in the 10 lowest $\mathrm{CH}_{4}$ values on the respective track. We calculate mixed layer uncertainty from the difference in number density between the lower limit and most likely limit of the mixed layer height using virtual potential temperature and the profiles of $\mathrm{CH}_{4}$ and $\mathrm{CO}_{2}$ (Figures $\mathrm{S} 1-\mathrm{S} 4$ ). This represents a conservative estimate as the difference in the number density of air is greater for a comparison with the lower limit of the mixed layer than a comparison with the upper limit. Lower limits ranged between 20-35 meters below the mixed layer. We assume these values represent two standard deviations. A total measurement uncertainty estimate is made by propagating the errors in upwind and downwind fluxes.

To account for inconsistent and non-negligible upwind fluxes and variable methods in assigning background values we (1) calculate net fluxes from our study sites using the difference between downwind and upwind fluxes and (2) develop an ensemble approach that considers multiple methods to assign background values and the sensitivity of net fluxes to different upwind fluxes. We assume the standard deviation between approaches on each lap represents methodological error.

A total regional flux estimate is made for each box using a selected mass balance approach and propagating measurement and methodological uncertainty. Our selected approach represents the simplest method amongst the ensemble and assumes the lowest concentration value on the full lap around the box represents background concentrations. We add methodological and measurement error in quadrature on each lap to calculate a total lap-level uncertainty for each estimate. Each lap is treated as an independent measurement and equally sampled from to generate a mean 10,000 times in a Monte Carlo simulation. The mean of the sampling distribution and $95 \%$ confidence intervals represent our final regional flux estimates.

\section{S6. Plume Attribution.}

We attribute two large plumes on downwind transects in Box A to platforms located upwind (AS4 and AS5) based on the width of the plume and direction of the wind field. This assumes the plume is generated from a point source and undergoes constant atmospheric conditions. We use a 
power law relationship between horizontal plume width and the distance of a point source modulated by assumptions of wind gustiness from Zannetti (1990) ${ }^{15}$. We find that if the plumes are related to sites AS4 and AS5 $(25 \mathrm{~km}$ and $12 \mathrm{~km}$ away), their cross wind widths $(6.7 \mathrm{~km}$ and $3.3 \mathrm{~km}$ ) are consistent with an atmospheric stability regime between neutral and unstable. This is fairly consistent with the standard deviation of horizontal wind speeds $\left(9.5^{\circ}\right)$, indicative of neutral conditions ${ }^{15}$.

\section{Supplementary Results and Discussion}

S7. Description of Official Inventories and Development of GHGI with Updated Platforms . Two U.S. inventories report emissions from offshore platforms in federal waters in U.S. Gulf of Mexico. Both the Bureau of Ocean Energy Management Gulfwide Offshore Activity Data System (GOADS) and Environment Protection Agency Greenhouse Gas Inventory (GHGI) estimate emissions in the outer continental shelf using bottom-up methodologies. GOADS uses equipment counts and throughput data, reported by operators in surveys, to estimate emissions at an equipment level on each platform. The GHGI develops emission factors by aggregating equipment-level emissions reported by GOADS to the platform-level and then averaging emissions into 4 production classes of platforms: shallow gas, shallow oil, and an identical emission factor for deep gas and deep oil ${ }^{16}$. At the time of the publication of this paper, the GHGI uses platform counts reported by the United States Minerals Management Service as activity data. Counts have not been updated since the Minerals Management Service was disbanded in 2010. Therefore, current GHGI estimates are constant from 2010-2017 ${ }^{17}$.

We recalculate the GHGI estimate at the regional and basin-level using EPA emission factors, new federal platform counts for $2018^{9}$, and production data ${ }^{12}$. We partition between shallow gas and shallow oil platforms based on whether platform-level production is oil or gas dominated using a gas oil ratio (GOR) of $10000 \mathrm{scf}$ gas/bbl oil, as previously used with cumulative GOR values in the Gulf of Mexico ${ }^{2}$. To do this, we link well-level production to above water platforms in GOADS based on pipeline data. We find that shallow water oil platforms in federal waters represent $44 \%$ of the shallow water platforms in Box A, $86 \%$ in Box B, and $71 \%$ in the federal Gulf of Mexico.

\section{S8. Discussion of Large Shallow Water Complexes.}

Throughput. Emissions from AS1, AS4, and AS5 represent a high loss rate compared to production volumes from surrounding wells. Figure $2 \mathrm{~b}$ shows that these facilities are surrounded by primarily caisson platforms, which send production volumes to the facility. Average emissions from AS1, AS4, and AS5 would be equivalent to a loss rate of 14\%, 151\%, and 56\% of natural gas production from nearby wells.

It is possible that throughput at these facilities includes transmission of deep water hydrocarbons. AS1 and AS5 are two facilities located in federal waters in Box A that are classified as 24-hour manned auxiliary platforms. Preexisting platforms included in this structure class are increasingly being co-opted for transmission of deep water oil and gas to shore ${ }^{2,3}$ (SI appendix $\mathrm{S} 1$.$) . AS4 is located in Louisiana state waters and not well documented, but is most likely$ manned for 24-hours considering the number of platforms in the complex needing operation (nine). It is possible that the high volumes of natural gas released at these facilities relative to 
total production in the box represents high throughput volumes from deep water. There are multiple 24-hour manned auxiliary platforms in Box A and B that may be associated with transmission of deep water hydrocarbons: at least 3 and 11 respectively.

Age. Large multi-platform complexes tend to contain old infrastructure. Current offshore platform infrastructure in the outer continental shelf Gulf of Mexico is 33+/-16 years old $(1 \sigma)$ in shallow water and 14+/-8 years old $(1 \sigma)$ in deep water. Multi-platform central hub facilities are composed of platforms of different ages with some facilities a mixture of very old and much newer platforms, exemplified by AS1 with platforms as old as 60 years and as new as 7 years. AS5 however, does not have as large a spread in age.

Distribution. Large shallow water facilities become increasingly common close to shore, particularly in Louisiana water (Figure 1). A number of central hub facilities in Louisiana state waters are included in the Louisiana Department of the Environmental Quality Emissions Reporting \& Inventory Center. While methane emissions are not included in this inventory, these facilities are large emitters of volatile organic compounds, with average facility-level emissions above the 60th percentile of point sources covered by the inventory ${ }^{18}$.

Cold vents and blowdowns. Cold vents present a plausible explanation for observed high emissions. The largest emission sources, reported by the 2014 GOADS, for central hub facilities in Box A are cold vents, fugitive losses, pneumatic pumps, and dehydrators. From among these, cold vent emissions show the most platform-level monthly variability, fluctuating by up to an order of magnitude, reminiscent of the daily emission variability shown in Table S1.

Considerable cold vent emissions are reported for both AS1 and AS5 and vent booms are visible in photos taken aboard facility-level flights at sites AS1 and AS4.

Blowdowns associated with facility-scale planned turnarounds and shutdowns are one mechanism capable of generating non-routine venting for extended periods. Individual blowdown events tend to occur on the scale of seconds to minutes ${ }^{19}$ with facilities equilibrating to atmospheric pressure on the scale of days ${ }^{20}$. However, these are major operations that require part or all of a platform's equipment to be suspended and are rare ${ }^{21}$, occurring about every 2-3 years ${ }^{22,23}$ per platform, lasting an average duration of 15 days ${ }^{24}$, and costing an average of 10 million U.S. dollars ${ }^{24}$. Blowdowns are also related to other activities, such as taking compressors off-line (which can occur frequently for peak-load compressors ${ }^{25}$ ), emergency shutdowns, or releasing accumulated gas in a shut in well.

The probability that we observed an infrequent non-routine emission event from all three facilities is low. For example, if we assume that every central hub platform undergoes abnormal operations that result in disproportionally high emission events 30 days per year with a duration of one day for each event then the probability of observing one or more high emission events is $54 \%$. However, the probability of observing three or more is only $3 \%$. Including a second day of samples in Box A decreases this probability to $0.008 \%$.

We estimate the probability of observing three or more infrequent emission spikes from central hub facilities using the equation below. 


$$
P(r \geq 3)=\sum_{r=3}^{n}\left(\begin{array}{l}
n \\
r
\end{array}\right) *(p)^{r} *(1-p)^{(n-r)}
$$

Where $r$ is the number of emission spikes observed, $n$ is the total number of emission spikes possible based on our sample of central hub facilities $(n=9), p$ is the probability of observing high emission spikes from a central hub facility $\left(p=\frac{30 \text { days }}{365 \text { days }}\right)$.

This calculation assumes abnormal events are independent between facilities. It is possible for a systematic venting event to occur from multiple facilities in response to a pipeline outage or extreme weather conditions. However, we do not believe we observed an anomalous venting event among the disproportionate emitters, as reported venting in federal waters for January 2018 within the lease containing AS1 and AS5 does not significantly deviate from other months in 2018.

\section{S9. Development of Producing and Non-producing Platform Segments in the Aerial Measurement-based Inventory.}

We develop a new bottom-up inventory to estimate facility-level emissions in the federal U.S. Gulf of Mexico and state waters in Louisiana, Texas, and Alabama. Emissions are estimated for producing platforms, non-producing platforms and minor sources, and the larges shallow water complexes. First, emissions from producing platforms are directly calculated using the loss rate curve shown in Figure S5. A distribution of curves (grey lines in Figure S5) are generated using the uncertainties in platform-level loss rates (error bars in Figures S5). Next a mean and 95\% confidence interval of $\mathrm{CH}_{4}$ emissions are generated using the distribution of emissions produced from the curves. In federal waters, we aggregate production to platforms by relating the welllevel production data ${ }^{12}$ to above water platforms in GOADS using pipeline information from BOEM. We assume that producing caisson and well protector platforms had zero emissions. This assumption posits that these types of platforms with little to no equipment should have low emissions as it is unlikely that throughput passes through above water infrastructure. This is consistent with trends in Figure S6 and samples shown in Table S1.

In state waters, we do not have access to recent platform locations, and instead create our own spatial inventory of production per platform using well data ${ }^{12}$. We assume that wells within a distance of 60 meters in very shallow water are related to the same platform and treated as one above water entity, while wells further than 60 meters are treated as separate. This assumption is tested and validated with a comparison of federal platforms in very shallow water reported by BOEM to platform counts created using adjacent wells. We assume that the ratio of non-emitting caisson and well protector platforms to emitting fixed platforms is the same in state waters as in federal waters and scale down our emission estimate by $25 \%$. This assumption may be incorrect and require revision.

Next, we estimate emissions from non-producing platforms in federal waters using existing estimates reported by GOADS. Our facility-level samples focused on producing platforms and the largest shallow water facilities, but did not sample emissions from other smaller central hub platforms or any other auxiliary platforms. Therefore, we rely on the 2014 GOADS estimate. It is possible that producing platforms that were active in 2014 and no longer active in 2018 are unintentionally included. We also include estimates by GOADS for caisson and well protector 
platforms in case there are some platforms with non-negligible pieces of equipment on them. We do not expect these to be an important contribution to this category. We do not offer an estimate of non-producing platforms in state waters as there is no aircraft or inventory information to draw upon.

\section{S10. Sampling Diversity and Expansion of the Aerial Measurement-based Inventory.} Heterogeneity in Platform and Production Characteristics. In Box A (shallow water), production is dominated by natural gas with an average production of $114,157 \mathrm{Mscf}$ gas/day and $2,954 \mathrm{bbl}$ oil/day ${ }^{12}$. Platforms consist of an equal number of minor caisson/well protector platforms and major fixed platforms, including at least five central hub facilities. On the other hand, production in Box B (shallow water) is focused on oil with an average production of 26,811 Mscf gas/day and 22,569 bbl oil/day ${ }^{12}$ and has fewer minor caisson/well protector platforms and double the number of major fixed platforms. Deep water platforms in Box C belong to a variety of deep water structure classifications and are focused on oil with high rates of production for both gas, 243,449 Mscf gas/day, and oil, 174,196 bbl oil/day ${ }^{12}$.

Extrapolation to Annual Basin-level Emissions. We make two crucial assumptions to extrapolate the aerial measurement-based inventory. First, we assume the inventory sufficiently captures platform heterogeneity. The validation of the aerial measurement-based inventory against regional fluxes supports this assumption. Regional-level flights sampled a substantial number of platforms located in federal waters. As a percentage of total active platform counts in federal waters reported during the time of the flights ${ }^{9}$ (and platforms included the 2014 GOADS inventory) we sampled a cumulative $13 \%$ (11\%). In addition, a diversity of platform characteristics are captured, including different production rates, platform types, ages, and whether production and processing operations are separate (Box A) or tend to be co-located (Box $\mathrm{B}$ and $\mathrm{C})$.

Second, we assume that basin-level emissions are relatively constant. We find little evidence to expect strong monthly or diurnal patterns at the basin-level in offshore oil and gas activity related to $\mathrm{CH}_{4}$ emissions. On average, monthly platform-level gas production rates are similar to annual rates, but we note a high standard deviation ${ }^{12}$. In addition, monthly equipment activity for dominant sources of $\mathrm{CH}_{4}$ in the GOADS inventory (cold vents, fugitives, and pneumatic pumps) is consistent between months in aggregate. According to GOADS equipment active hour counts, most of these major equipment sources of $\mathrm{CH}_{4}$ are considered active almost constantly, except for pneumatic pumps, which are active about half of the time and thus may have a diurnal component. In 2016, over 600 platforms were manned for 24 hours $^{2}$ (found in both shallow and deep water), suggesting that important centers of activity are active all day. With a sample size of over $10 \%$ of platforms in the Gulf of Mexico, we expect that temporal variations at the platformlevel are averaged out.

\section{S11. Development of Emission Factors Analogous to the GHGI.}

We develop three emission factors that reflect unique categories used by the GHGI that encompass all platform emissions. Our emission factors are calculated for federal waters using emissions estimated by the aerial measurement-based inventory for the outer continental shelf and total active federal platform counts in the Gulf of Mexico during January 2018 (43 in deep 
water and 1924 in shallow water) ${ }^{9}$. Since the two GHGI deep water emission factors are identical we treat them as one emission factor. First, platforms are classified as shallow water or deep water based on structure type rather than depth as the shallow-deep water boundary marks a shift in platform structure types (see Figure 1). We find similar counts if depth were instead used as ocean depth quickly drops around this boundary.

To isolate emissions associated with producing shallow gas from shallow oil platforms, we use a GOR of 10,000 scf gas/bbl oil per platform. Emissions associated with shallow non-producing platforms and minor sources, and the largest shallow water complexes are equally distributed among all shallow water platforms. We estimate total counts of shallow gas and shallow oil platforms using the ratio of producing shallow gas to shallow oil platforms, assuming the ratio is representative of all platforms, as done with the updated GHGI estimate (see SI appendix S7). 

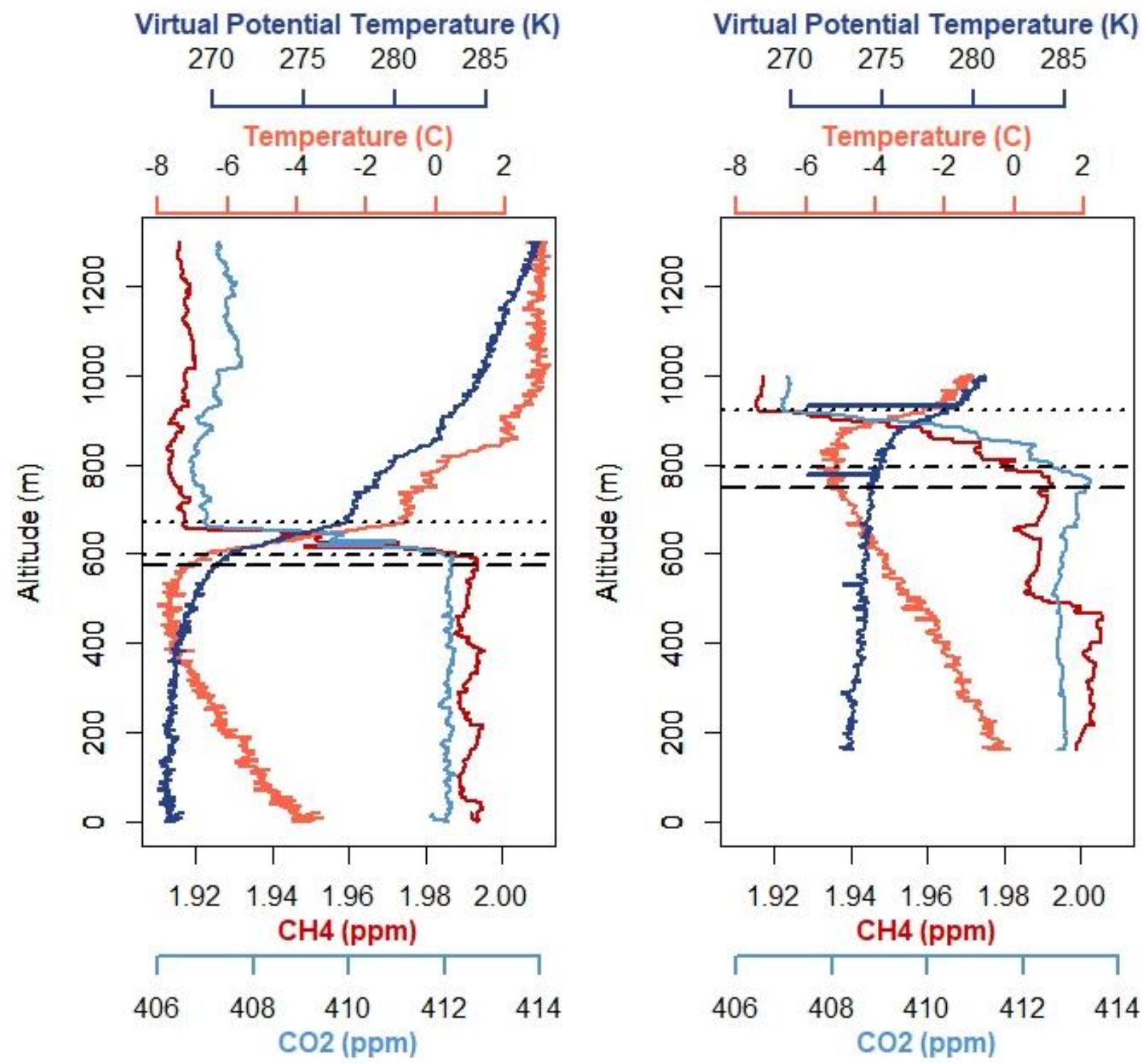

FIGURE S1. Vertical Profiles on January $17^{\text {th }}$ in Box A. Lines show the heights of the mixed layer (dashed line), the adjusted mixed layer (dotted and dashed line), and the free troposphere (dotted line). The left profile was taken west of the box using a downward hybrid loop and transect flight path taken over $13.5 \mathrm{~km}$ during 12 minutes. The right profile was taken four hours later on the northeast quadrant using an upward transect flight path taken over $15 \mathrm{~km}$ during four minutes. Note that we have removed the bottom section of the profile on the right as $\mathrm{CH}_{4}$ concentrations were influenced by a facility sampled preceding the profile. 

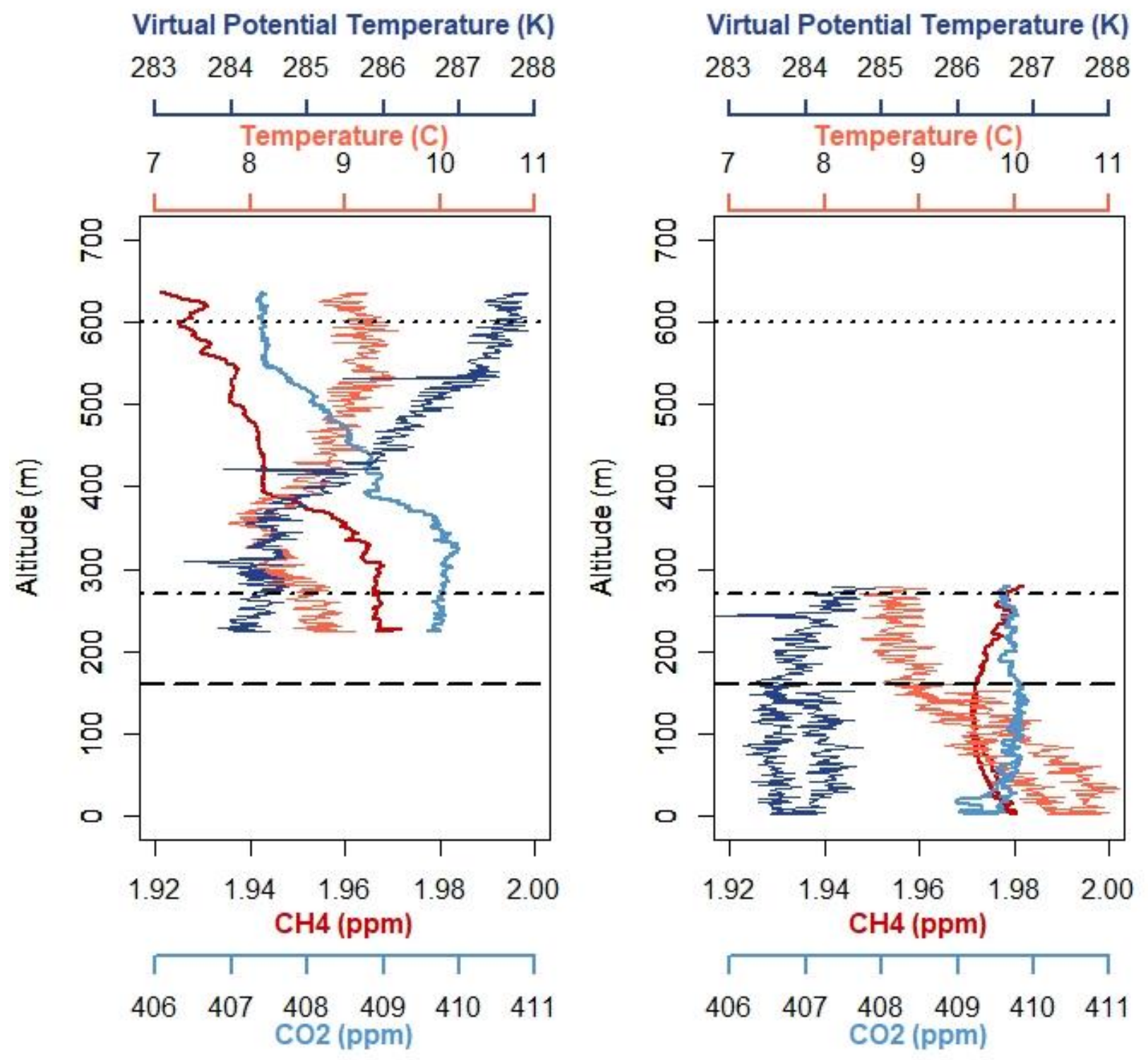

FIGURE S2. Vertical Profiles on January $19^{\text {th }}$ in Box B. Lines show the heights of the mixed layer (dashed line), the adjusted mixed layer (dotted and dashed line), and the free troposphere (dotted line). The left profile was taken on the northeast corner of the box using an upward loop flight path taken over three $\mathrm{km}$ during four minutes. The right profile was taken 30 minutes later on the northeast corner of the box using first a downward and then upward loop flight path taken over $3.5 \mathrm{~km}$ during four minutes. 

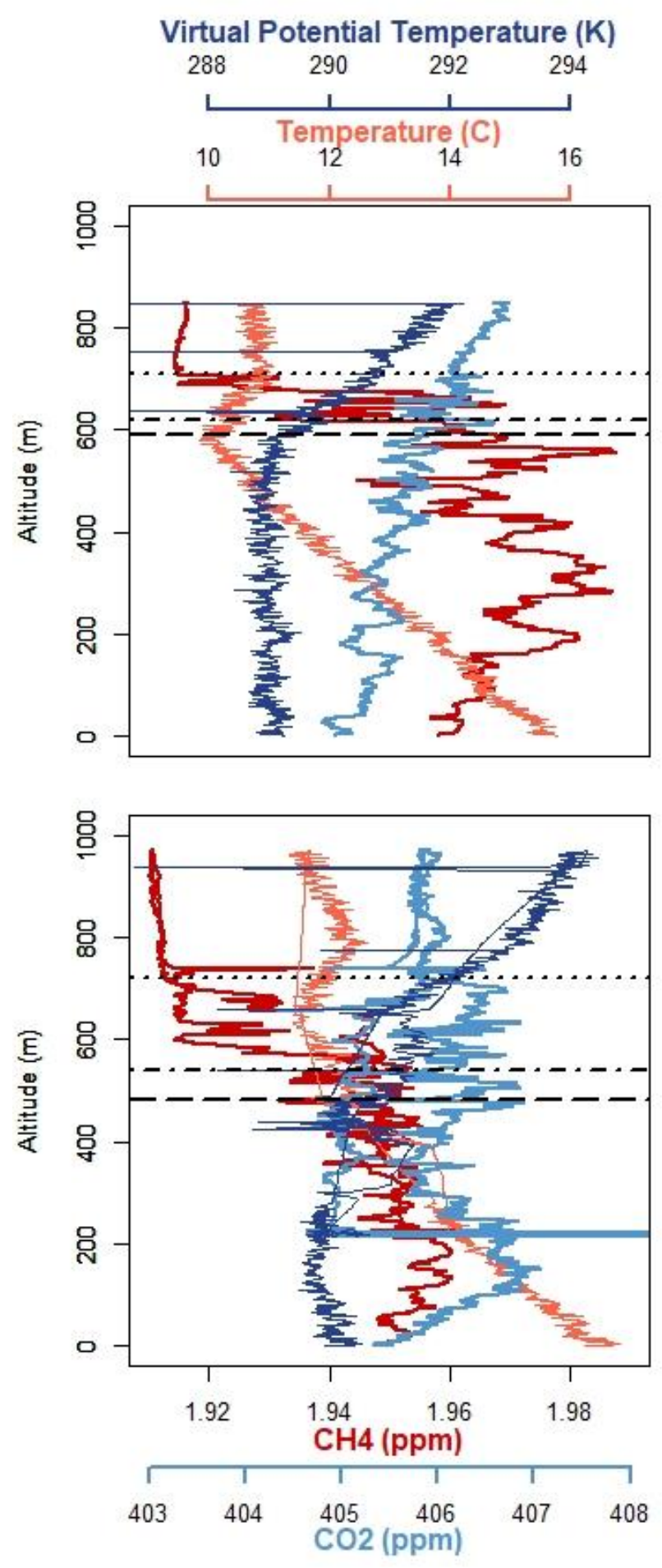

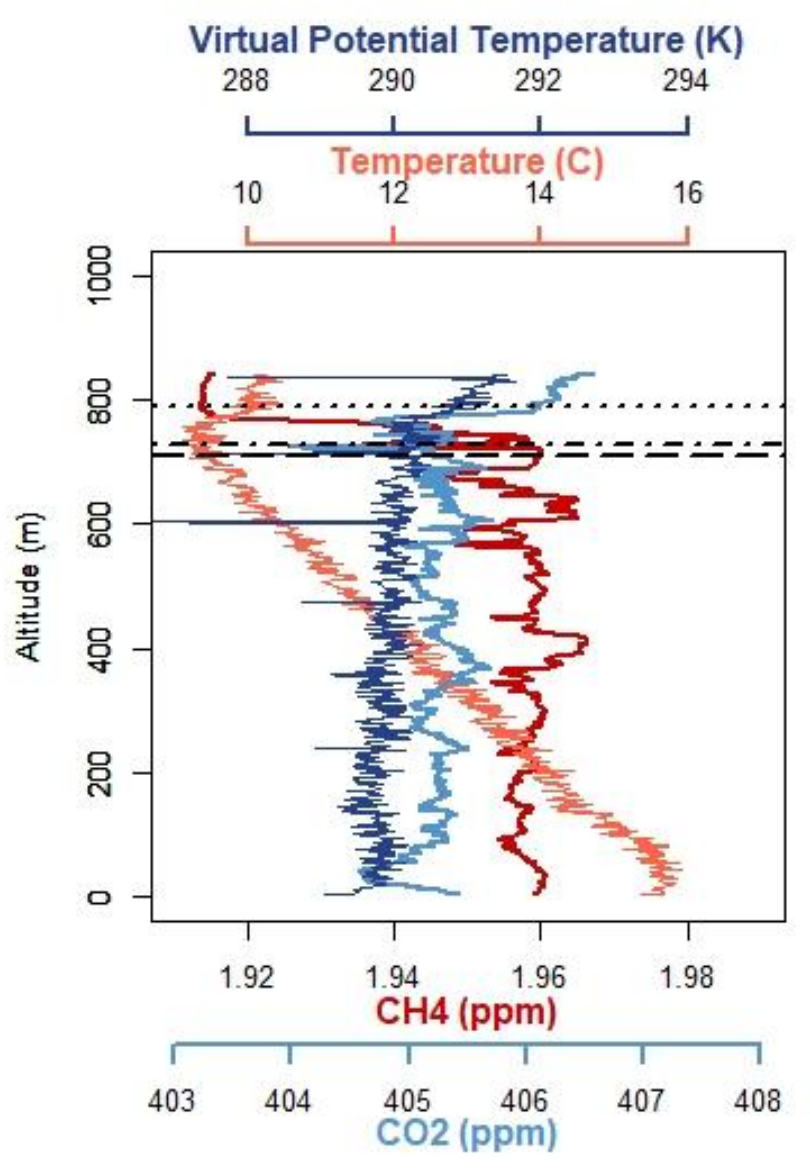

FIGURE S3. Vertical Profiles on January $23^{\text {rd }}$ in Box C. Lines show the heights of the mixed layer (dashed line), the adjusted mixed layer (dotted and dashed line), and the free troposphere (dotted line). The top left profile was taken west of the box using a downward transect flight path taken over $42 \mathrm{~km}$ during eight minutes. The top right profile was taken one hour later west of the box using an upward loop flight path taken over three $\mathrm{km}$ during seven minutes. The bottom left 
profile was taken two hours later west of the box using an upward and then downward hybrid loop and transect flight path taken over $11.5 \mathrm{~km}$ during 15 minutes. 

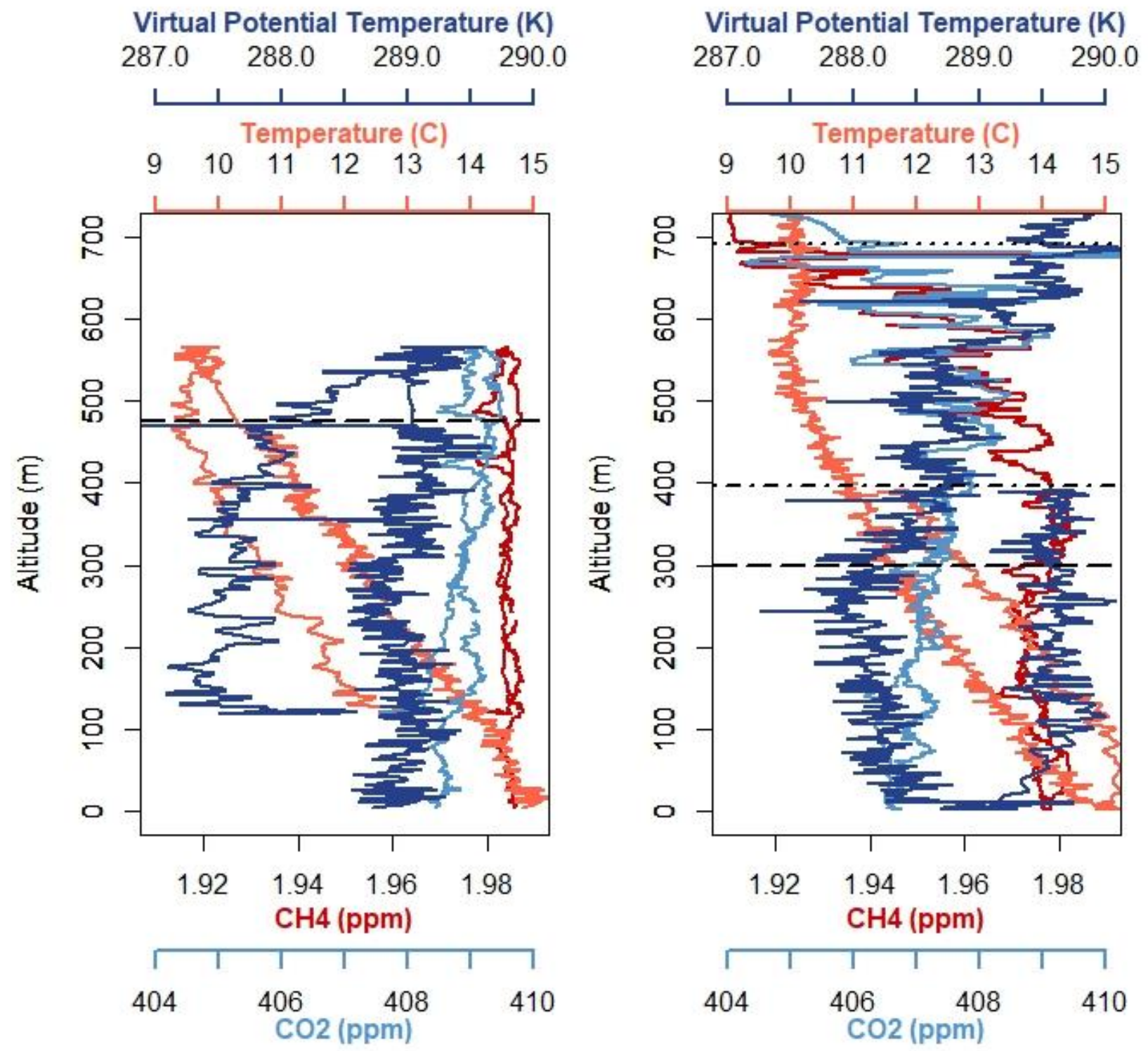

FIGURE S4. Vertical Profiles on January $24^{\text {rd }}$ in Box C. Lines show the heights of the mixed layer (dashed line), the adjusted mixed layer (dotted and dashed line), and the free troposphere (dotted line). The left profile was taken west of the box using an upward and then downward loop flight path taken over $3.5 \mathrm{~km}$ during seven minutes. The right profile was taken west of the box using a downward and then upward loop flight path taken over four km during eight minutes. 


\section{Leakage Curve for Producing Platforms}

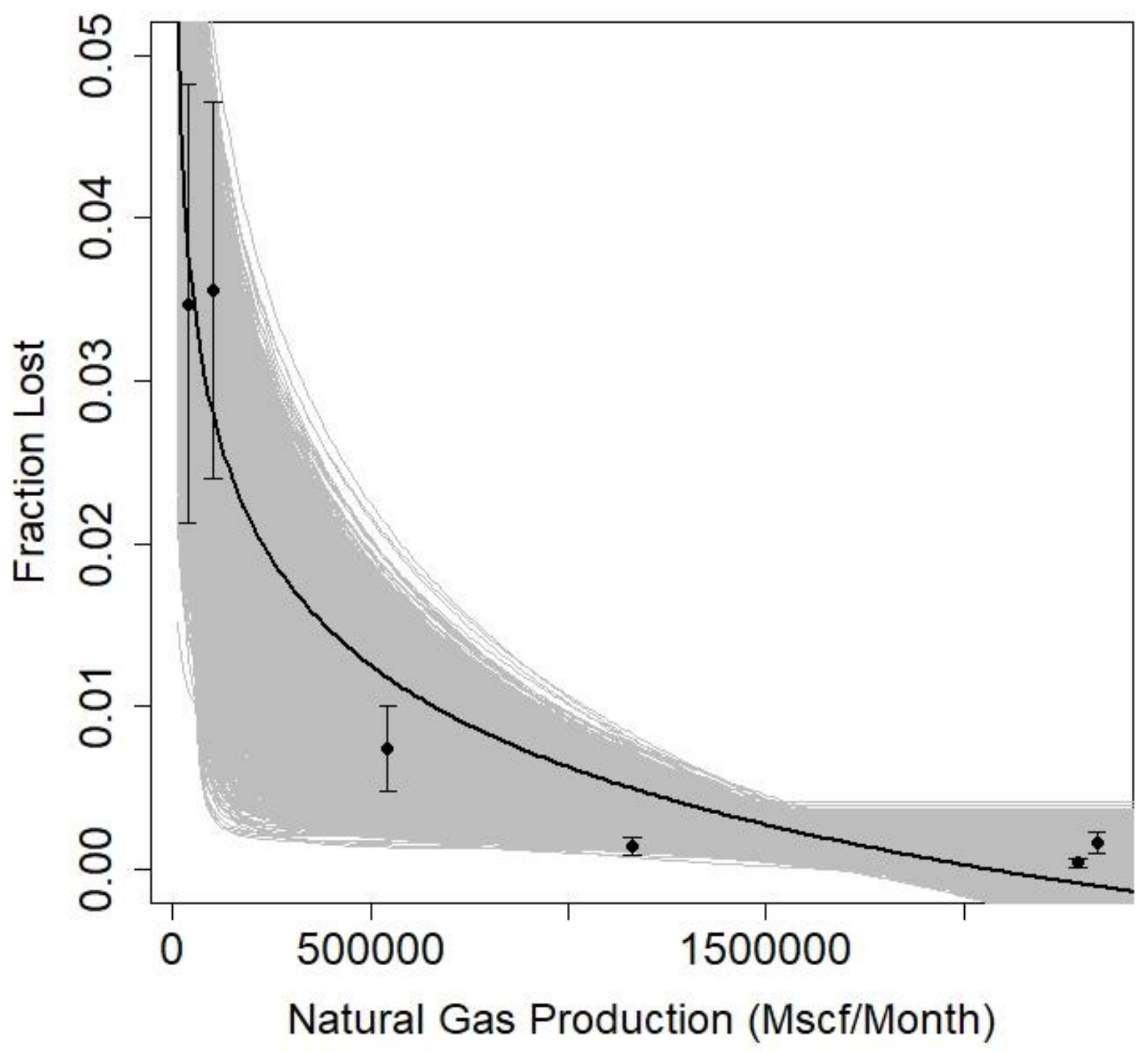

FIGURE S5. Loss rate curve (black line) for producing platforms sampled during the facilitylevel measurements (circles). An ensemble of curves (grey lines) are generated from the standard deviations (error bars). 


\section{Platform Methane Emissions}

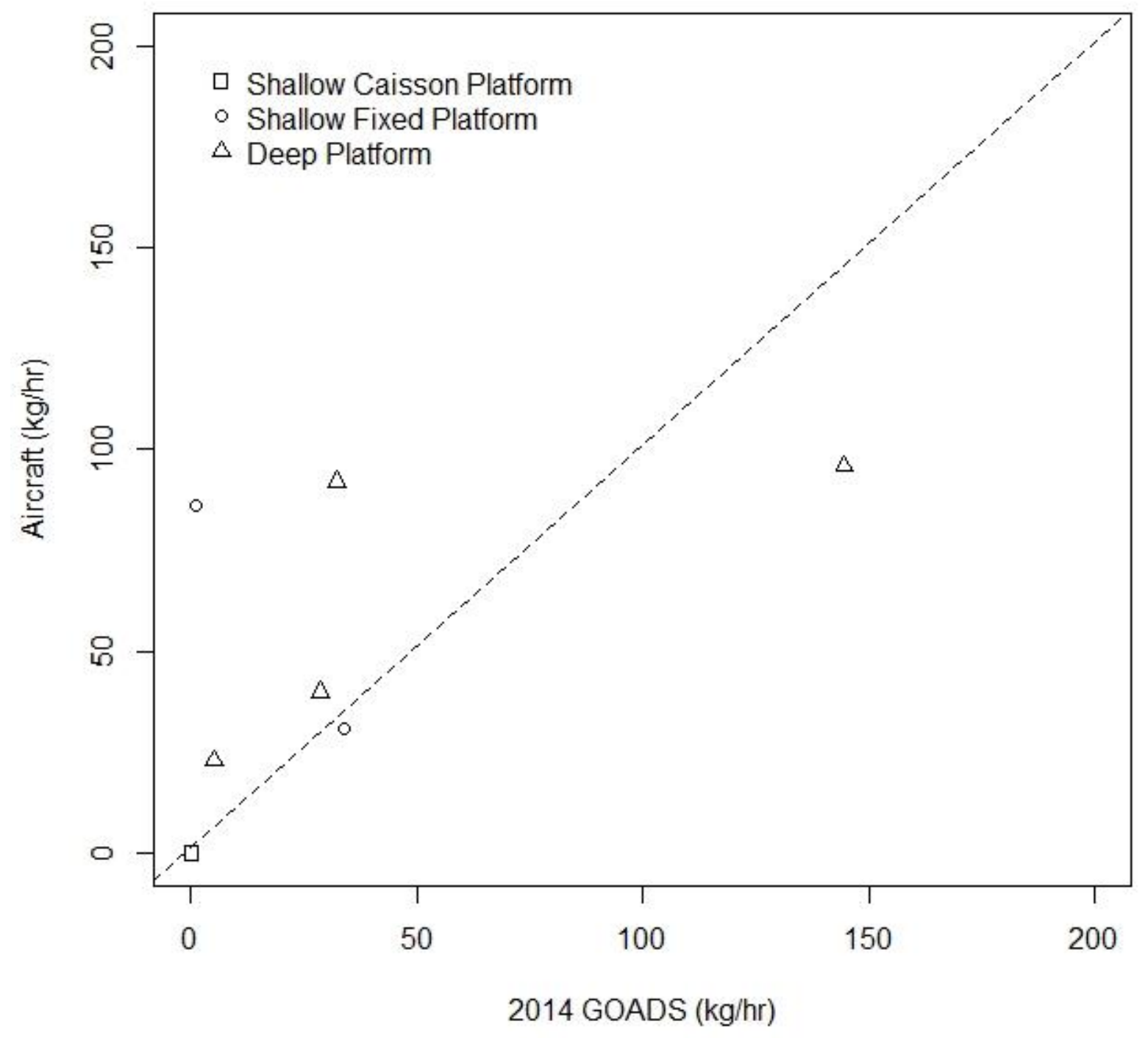

FIGURE S6. Comparison of emission rates excluding large shallow water complexes. 


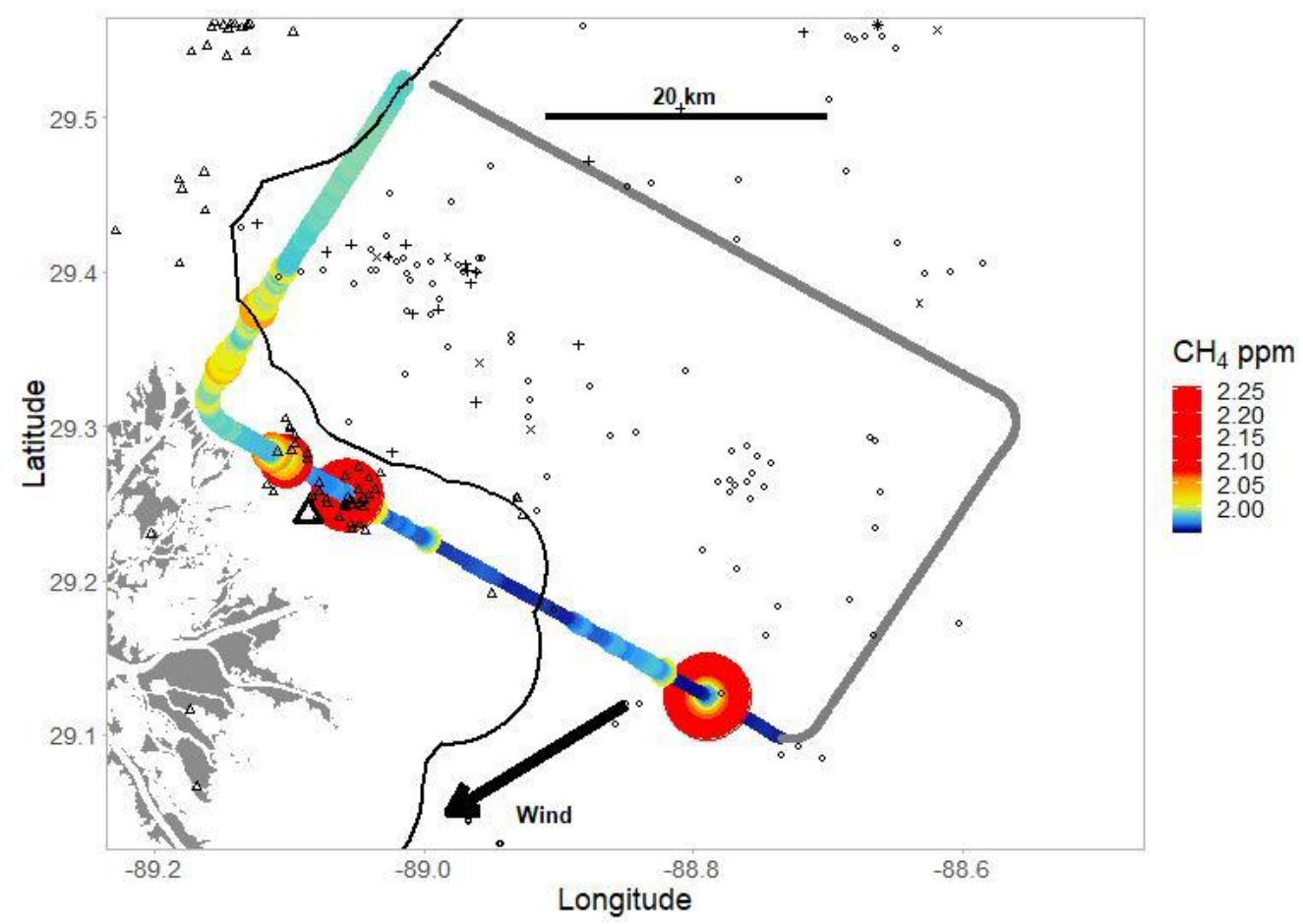

FIGURE S7. Downwind regional flux transect for Box B on January $19^{\text {th }}$. Aircraft tracks (lines), downwind methane concentrations (color scale), and wind direction (arrows) are shown. Points correspond to platform classifications described in Figure 1. The federal-state water outer continental shelf boundary is mapped (black line). 


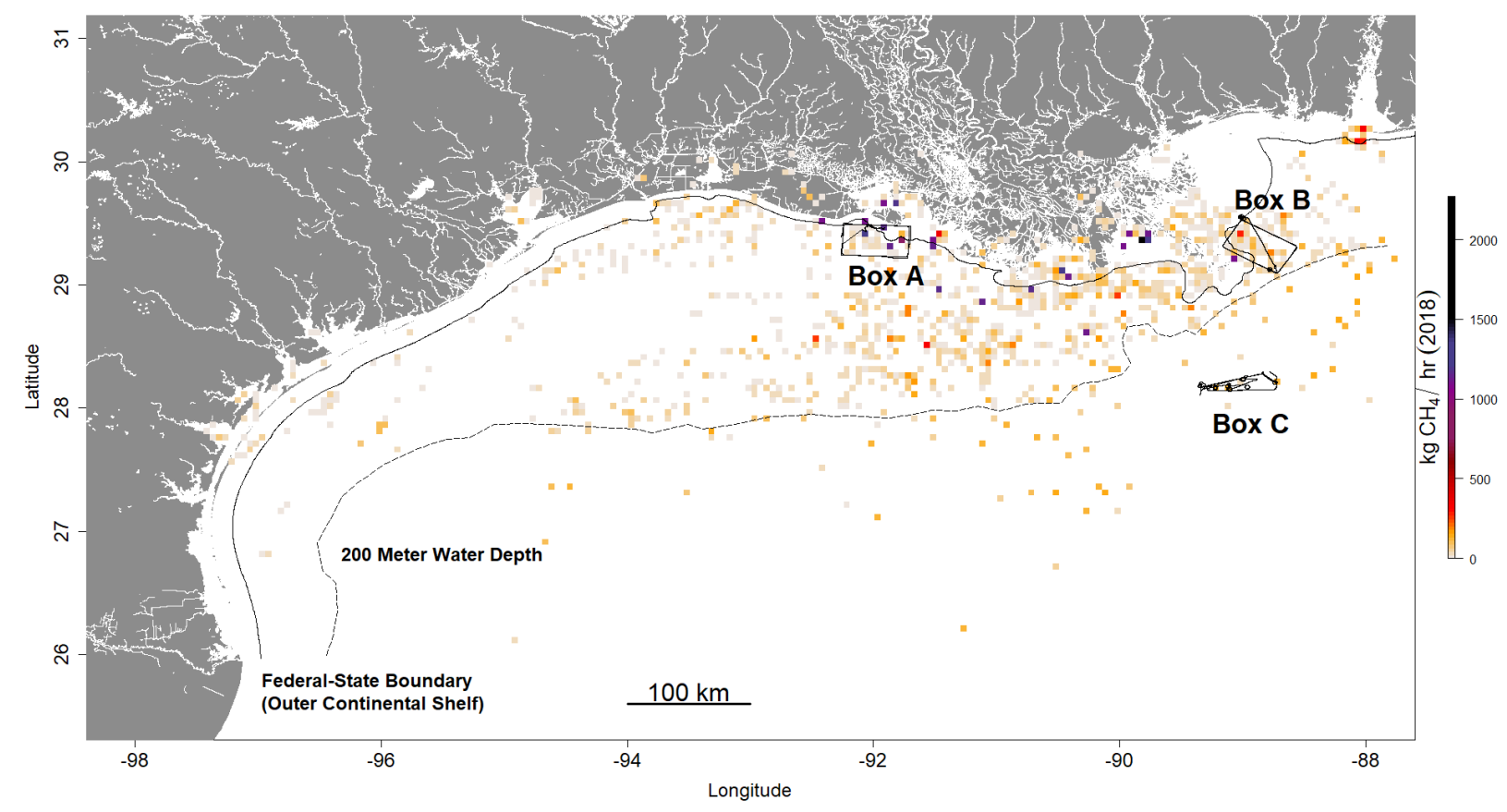

FIGURE S8. Map of aerial measurement-based inventory in the U.S. Gulf of Mexico. Facilitylevel fluxes are aggregated to $0.05^{0} \mathrm{X} 0.05^{0}$ resolution. 


\section{Aerial Measurement-based Inventory}

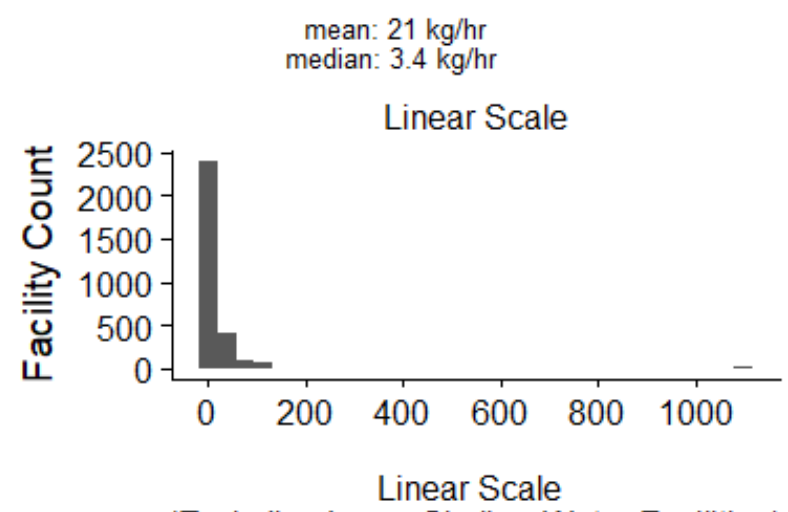

(Excluding Large Shallow Water Facilities)
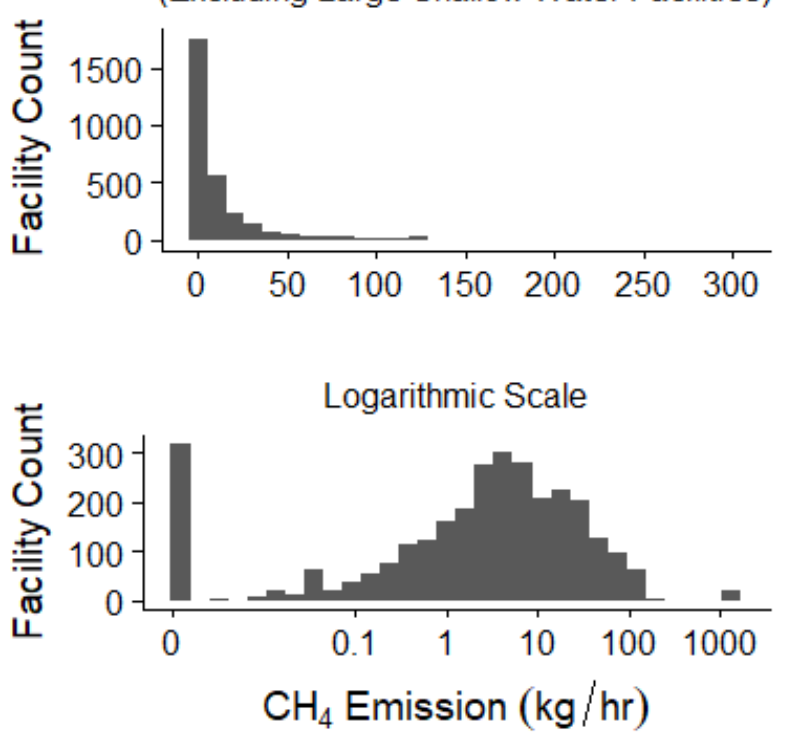

Yacovitch et al. (2020)

(Excluding Drill Ships)

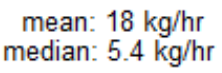

median: $5.4 \mathrm{~kg} / \mathrm{hr}$
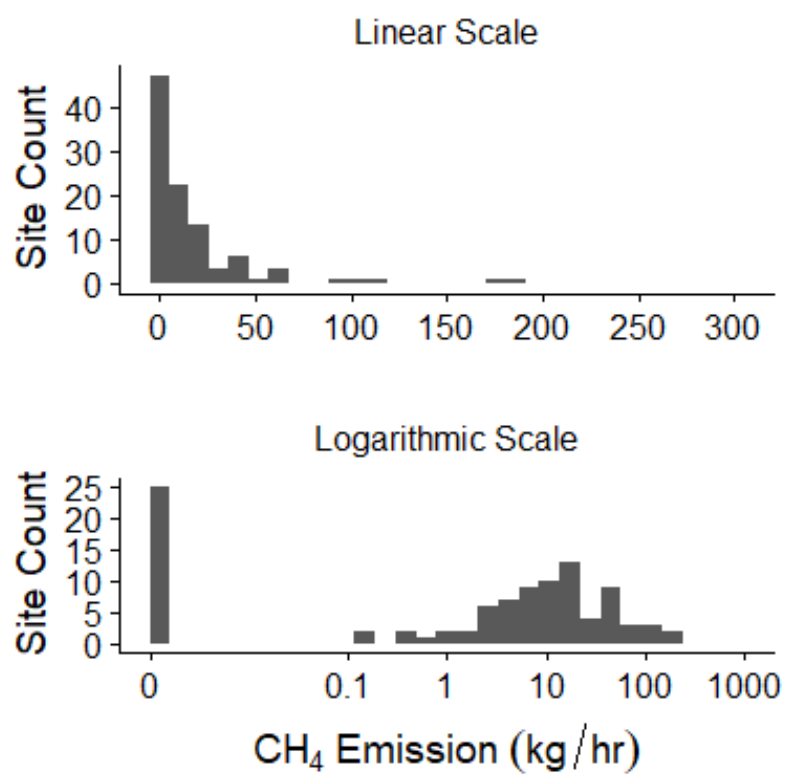

FIGURE S9. Emission rate frequency distribution for the aerial measurement-based inventory for the full U.S. Gulf (left) and Yacovitch et al. (2020) ${ }^{26}$ (right). Histograms are plotted on a linear scale (top and middle) and logarithmic scale (bottom). The mean and medians are shown for all platforms including platforms with zero emissions. 
TABLE S1. Facility-level $\mathrm{CH}_{4}$ Emissions

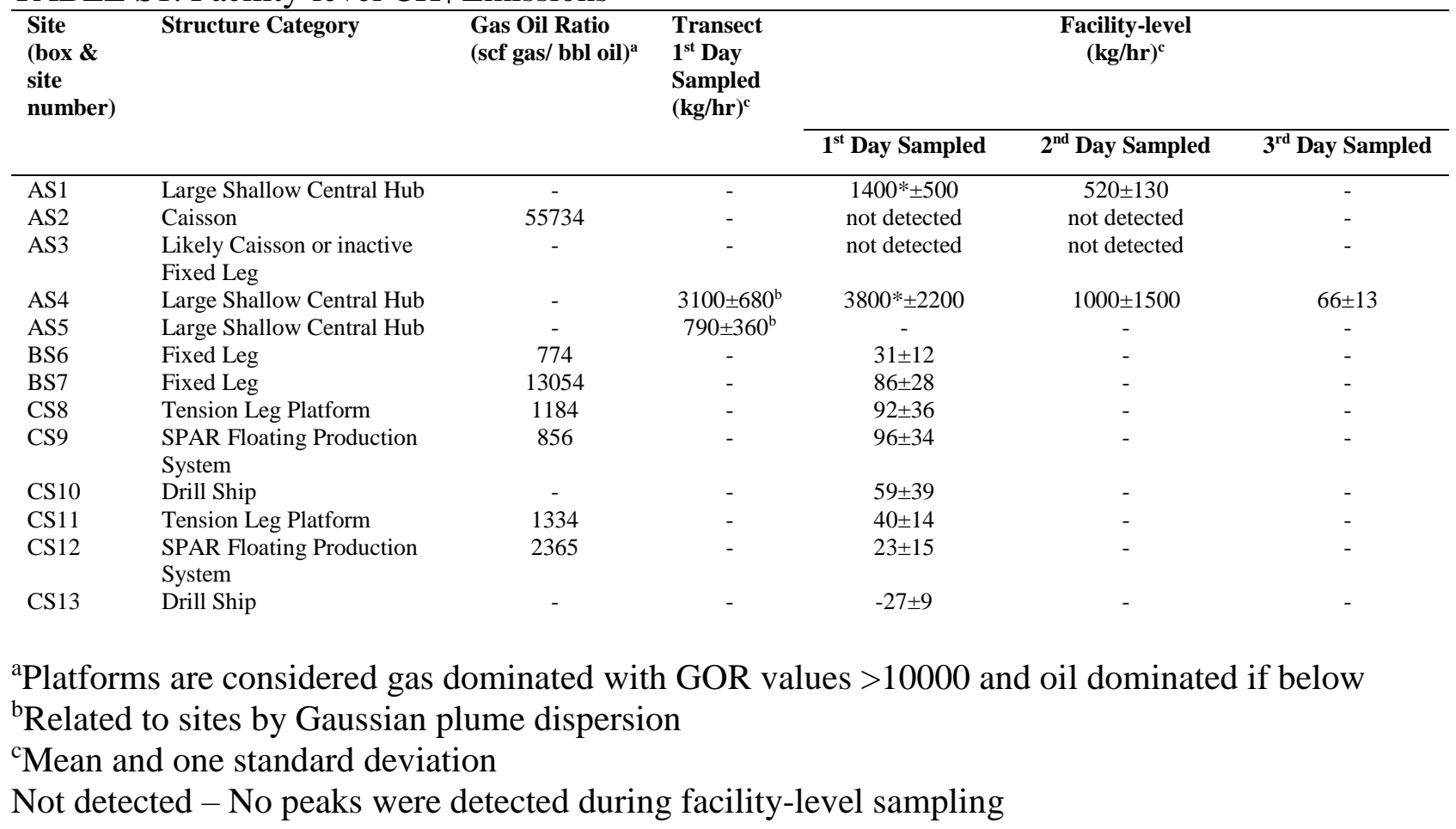




\section{REFERENCES}

1. Kaiser, M. J., US Gulf of Mexico deepwater pipeline construction - A review of lessons learned. Marine Policy 2017, 86, 214-233.

2. Kaiser, M. J., A review of shallow water structures in the U. S. Gulf of Mexico circa 2016. Ships and Offshore Structures 2018, 13 (7), 677-695.

3. Kaiser, M. J.; Narra, S., A hybrid scenario-based decommissioning forecast for the shallow water US Gulf of Mexico, 2018-2038. Energy 2018, 163, 1150-1177.

4. Crosson, E. R., A cavity ring-down analyzer for measuring atmospheric levels of methane, carbon dioxide, and water vapor. Applied Physics B-Lasers and Optics 2008, 92 (3), 403-408.

5. Karion, A.; Sweeney, C.; Kort, E. A.; Shepson, P. B.; Brewer, A.; Cambaliza, M.; Conley, S. A.; Davis, K.; Deng, A. J.; Hardesty, M.; Herndon, S. C.; Lauvaux, T.; Lavoie, T.; Lyon, D.; Newberger, T.; Petron, G.; Rella, C.; Smith, M.; Wolter, S.; Yacovitch, T. I.; Tans, P., Aircraft-Based Estimate of Total Methane Emissions from the Barnett Shale Region. Environmental Science \& Technology 2015, 49 (13), 8124-8131.

6. 2B Technologies Model 205 Dual Beam Ozone Monitor. https://twobtech.com/model205-ozone-monitor.html (accessed March 21).

7. Conley, S. A.; Faloona, I. C.; Lenschow, D. H.; Karion, A.; Sweeney, C., A Low-Cost System for Measuring Horizontal Winds from Single-Engine Aircraft. Journal of Atmospheric and Oceanic Technology 2014, 31 (6), 1312-1320.

8. Bureau of Ocean Energy Management Platform/Rig Information. https://www.data.boem.gov/Main/Platform.aspx (accessed January 1).

9. United States Bureau of Safety and Environmental Enforcement BSEE Data Center: Offshore Statistics by Water Depth. https://www.data.bsee.gov/Leasing/OffshoreStatsbyWD/Default.aspx (accessed March 12). 10. Bureau of Ocean Energy Management Pipeline Information. https://www.data.boem.gov/Main/Pipeline.aspx (accessed September 15).

11. Bureau of Safety and Environmental Enforcement Oil and Gas Operations Reports - Part B (OGOR-B) Lease Disposition 1996-Current. https://www.data.bsee.gov/Main/OGOR-B.aspx (accessed December 10).

12. Drillinginfo, DI Desktop 2019 Drillinginfo.

13. Conley, S.; Faloona, I.; Mehrotra, S.; Suard, M.; Lenschow, D. H.; Sweeney, C.; Herndon, S.; Schwietzke, S.; Petron, G.; Pifer, J.; Kort, E. A.; Schnell, R., Application of Gauss's theorem to quantify localized surface emissions from airborne measurements of wind and trace gases. Atmospheric Measurement Techniques 2017, 10 (9), 3345-3358.

14. Peischl, J.; Karion, A.; Sweeney, C.; Kort, E. A.; Smith, M. L.; Brandt, A. R.; Yeskoo, T.; Aikin, K. C.; Conley, S. A.; Gvakharia, A.; Trainer, M.; Wolter, S.; Ryerson, T. B., Quantifying atmospheric methane emissions from oil and natural gas production in the Bakken shale region of North Dakota. Journal of Geophysical Research-Atmospheres 2016, 121 (10), 6101-6111.

15. Zannetti, P., Gaussian Models. In Air Pollution Modeling, Springer Science+Business Media: New York, 1990.

16. Environmental Protection Agency Inventory of U.S. Greenhouse Gas Emissions and Sinks 1990-2013: Revision to Offshore Platform Emissions Estimate; 2015.

17. United States Environmental Protection Agency Greenhouse Gas Emissions and Sinks: 1990-2017; EPA: 2019. 
18. Louisiana Department of the Environmental Quality, Emissions Reporting \& Inventory Center. 2019.

19. Lawrence, P.; Marriott, J.; Giovanoglou, A.; Process Systems Enterprise, Ensuring Safe Facility Blowdown and Lessons Learnt from Incident Investigation. In SPE Asia Pacific Oil \& Gas Conference and Exhibition, Society of Petroleum Engineers: Perth, Australia, 2016.

20. Zhi, X.; Xiaohong, Z.; Zhijun, L. Y.; un, H.; Rongqi, C.; Research; Corp., I. o. C. N. O. O., Study and Application of Production Relief and Blowdown on the Large-Scale Offshore Oil and Gas Fields. In Offshore Technology Conference, Offshore Technology Conference: Houston, Texas, USA, 2013.

21. Aviation Safety Support Services for the Bureau of Safety and Environmental Enforcement Study on Effects of Combustible Gas on Helicopter Operations; 2015.

22. Berdahl, I. L. Turnaround strategy development: a case study. Norges teknisknaturvitenskapelige universitet, Norges teknisk-naturvitenskapelige universitet, Fakultet for ingeniørvitenskap og teknologi, Institutt for marin teknikk, 2011.

23. Binti Zaina Abidin, N. A.; Binti Khairil, N. N. A.; Binti Abdul Rahani, N. R.; Binti Shafee, S.; Binti Mohd Zahid, N. A., A study on logistic setup challenges during a schedule offshoreplatform shutdown in Petronas Carigali Kerteh, Terengganu. International Journal of Entrepreneurial Research 2019, 2 (1).

24. Dickey, L.; Flesch, C. E.; Jordan, J. D.; Inacio, F., Reducing Impact of E\&P Shutdowns. In Offshore Technology Conference, Offshore Technology Conference: Houston, Texas, USA, 2011.

25. Bylin, C.; Schaffer, Z.; Goel, V.; Robinson, D.; do N. Campos, A.; Borensztein, F., Designing the Ideal Offshore Platform Methane Mitigation Strategy. In SPE International Conference on Health, Safety and Environment in Oil and Gas Exploration and Production, Society of Petroleum Engineers: Rio de Janeiro, Brazil, 2010.

26. Yacovitch, T. I.; Daube, C.; Herndon, S. C., Methane Emissions from Offshore Oil and Gas Platforms in the Gulf of Mexico. Environmental Science \& Technology 2020. 